\title{
Santuarios y entornos sagrados en Chipre. Del período geométrico al final del clasicismo
}

\author{
Javier Burgaleta Mezo
}

La intención de estas páginas es presentar una breve recapitulación de santuarios y "contextos" religiosos, que sirva a su vez para introducirnos, mediante una visión "topográfica", en el resbaladizo tema de las hierofanías que en ellos se producian, del panteón que los ocupaban (o al menos, de los nombres que sucesivamente fueron recibiendo), en un lugar como Chipre, donde la convivencia y la aculturación son tan señaladas. En realidad, presentamos una documentación que habrá de servir para una futura evaluación de la persistencia y de los cambios religiosos culturales respecto de su «protagonista pasivo": la divinidad a la que se dirigía el culto ${ }^{1}$.

En tal sentido, el santuario puede resultar un testigo excepcional de los fenómenos de convivencia, superposición y asimilación de las diferentes culturas y sus respectivos cultos que se dieron en la isla, ya que en él se plasman de alguna manera los resultados de todo ello, quizás más

- Éste seria un campo independiente a desarrollar, tratando de resaltar las líneas principales dentro de las que se mueven tales manifestaciones - a un nivel de teoria de la religión- a lo largo del desarrollo cultural, desde una religión prehistórica a otra que finalmente concluye en procesos de conformación de estados. Sin embargo, vamos a centrarnos en la manifestación concreta del cambio y la pervivencia de elementos divinos, de esencias y atributos, en la medida en que ello es posible teniendo en cuenta la documentación existente. Sobre Chipre como lugar de convivencia, v. Hermary, A., (1987, pág. 388.) 
significativamente que en utra clase de documentos aislados, adquiriendo en este marco un sentido más completo ${ }^{2}$.

Antes de proseguir, es necesario aclarar que precisamente, usamos el término "contextos" (o "entornos") sagrados para referirnos a aquellos lugares donde no se han conservado, o nunca existieron, restos de una construcción templar, pero han proporcionado inscripciones o materiales arqueológicos con un significado religioso implícito, tal como figurillas, etcétera, que bien pueden proceder de un depósito sagrado («bothros" o "favissa") asociable a él por sus características, etc. Un santuario puede componerse sólo de un "témenos", recinto sagrado delimitado o no de alguna manera, o incluso, consistir sencillamente en un lugar venerado bajo alguna forma natural en sí: roca, fuente, árbol ${ }^{3}$.

Queremos aclarar también las consideraciones observadas al agrupar unos sitios con otros. El santuario rural, generalmente elemento aislado, es tratado, naturalmente, "per se", mientras que los urbanos lo son en el conjunto de la ciudad, en vez de hacerlo independientemente. Pero hemos agrupado también dentro de los conjuntos urbanos aquellos casos de santuarios extramuros, cuya proximidad al núcleo urbano los haria muy probablemente participes en su vida religiosa. El mismo hecho de la diferenciación entre santuarios rurales y urbanos, da pie para hacer ciertas observaciones. Esta diferencia procede, o se acentúa, precisamente en el momento en que se produce la extensión, sino la gestación, del urbanismo, como sucede en Chipre en la Edad del Hierro, junto a la emersión de los reinos históricos que conocemos. Determinar en que consisten esas diferencias y el particularismo de los santuarios rurales, es asunto complejo. A. Caubet (1986, p. 167) al estudiar los de Kitión,

2 Teniendo en cuenta esta premisa, trataremos de contextuar los santuarios que nos ocupan mediante las observaciones que consideremos pertinentes, prescindiendo en lo posible de prodigar referencias que se encuentran en las publicaciones arqueológicas. Se da en efecto la posibilidad de estudiar los santuarios teniendo en cuenta aspectos como su morfologia y tipologia. Como parte de una cultura y de unas concepciones religiosas, y expresión de ambas. Si por otra parte el santuario, como una parte más del conjunto arqueológico proporciona material para la elaboración de ese discurso arqueológico, todas aquellas cuestiones referidas a paralelos, constitucción, etc., no serán mencionados.

3 Es bien sabido que en las religiones antiguas: elementos naturales recibian una veneración especial, que determinados lugares eran especialmente aptos para ciertos cultos: cuevas, colinas, y que bastaba con que se acondicionasen someramente. El templo, que como casa del dios cobijaba una estatua, era sólo una parte del complejo religioso, no imprescindible, bien es cierto. Cf. los casos cretense, minoico, oriental, que tanta influencia tienen en Chipre. Concretamente, el caso cretense es origen de elementos de la coroplástica chipriota, como las figurillas de diosas con manos en alto, falda acampanada, etc., subminoicas. 
apunta la duplicidad entre los extramuros y los intramuros, en una aparente simetría, y se interroga sobre una relación de subordinación funcional, o quizás un uso conjunto en determinadas fiestas. Pero indica a la vez la imposibilidad de confirmar de momento semejantes propuestas, consciente de las dificultades inherentes. La explicación de aquellos otros enclavados en lugares más remotos serían otras, como trataremos de explicar, derivadas del devenir histórico. Una primera cuestión es si en tales casos quedaría determinado a una clase de culto particular y diferenciado. Se podría contestar afirmativamente, en tanto a sus fieles se les suponga una diferencia de tipo social, cultural o incluso étnica. Pero no es así siempre. El campo forma parte de un "hinterland» urbano, con el que se comunica constantemente, por lo que no siempre se da semejante separación, sino más bien alguna clase de integración. Habría que hacer una gradación de su importancia y del reconocimiento que recibe en la ciudad.

Pero estas consideraciones no obvian en ningún caso la independencia del mundo rural, ámbito a veces más propicio para la hierofania que el urbano. El componente naturalista de la religión encuentra su expresión inmediata en la misma naturaleza. En efecto, la importancia de lo topográfico y su percepción particular por cada individuo y cultura es parte esencial de la dinámica que genera la percepción de lo divino, su manifestación. Se trata de valorar la importancia de lo topográfico "per se" ${ }^{4}$.

Existe, finalmente, un problema de superposición de culturas, en tanto estas se suceden en la ocupación simbólica del territorio, y por tanto, se producen inflexiones entre medio físico y la experiencia numinosa cultural. Es decir: a) el reconocimiento en ese medio de nuevos contextos para una experiencia numinosa que ha cambiado, y entonces esto no presupone un cambio étnico, sino cambios cualitativos dentro de una cultura que anteriormente lo ocupaba, o bien, b) el reconocimiento del territorio como un nuevo contexto, si hablamos de una irrupción desde el exterior, esto es, de portadores de una nueva religión que buscarán nuevas referencias topográficas, nuevos lugares sacros, en el entorno recién descubierto.

Ello conduce al problema de las supervivencias, y al de las sucesivas advocaciones que asume la divinidad que ocupa el santuario, que podríamos esquematizar: a) de acuerdo con un proceso de evolución hacia un politeismo en el que se da una progresiva diferenciación funcio-

\footnotetext{
${ }^{4}$ A tal respecto, se puede traer a colación el caso cretense, con sus cultos en cuevas, etc., que por otra parte tanta influencia tuvo en Chipre.
} 
nal. Se pasa asi de una indeferenciación originaria a una especialización. En tanto la indiferenciación abarca o comprende a la especialización, por el mayor abanico de funciones que asumía, se da, o puede darse, una cierta incongruencia entre la nueva divinidad especializada y los múltiples aspectos que se ponían bajo su protección (podemos constatar así unos cultos rendidos a una divinidad en aspectos más variados de los que le competen). Esto se resuelve adecuando el "tipo de demanda cultual" con la "oferta especializada del dios" (otros santuarios, sin embargo, pueden asumir desde el principio una parcela de culto 0 actividad concreta). b) Un segundo caso, de acuerdo con un proceso de sincretismo religioso de identificación de divinidades por sus funciones, rasgos, atributos, etc. Todo ello parece tener una aplicación real, en los numerosos casos de divinidades supuestamente antecesoras y polivalentes ${ }^{5}$.

Respecto de los santuarios urbanos, sin negar en ciertos casos una raiz preurbana, es decir, los casos de superviviencias y continuidad de lugares sacros preexistentes e integrados en el tejido urbano, es esencial comprenderlos e interpretarlos como parte del proceso de urbanización, y por tanto, de una mayor complejización social, con todos los cambios que ello implica, así como su integración en la vida pública de esas unidades políticas. Algunas cuestiones inherentes son por ejemplo, primero, la progresiva diferenciación del «témenos» o espacio sagrado dentro del tejido urbano, y su relación con la forma de poder político existente. Los lugares sagrados forman parte de estructuras sociales y de poder: grupos, monarquias. La ciudad se adecúa a unos lugares sagrados, preexistentes. Incluso, porque el lugar sagrado es un aglutinante, junto con otros factores, del inicio de la vida urbana: se convierte en centro de una atención, de una solidaridad: así el "témenos" se convierte en patrimonio de la comunidad, y la tumba del héroe epónimo agrupa unas primeras casas ${ }^{6}$.

Si la exposición seguida, una ordenación alfabética de santuarios y complejos sacros, trataba de evitar el problema de los cambios históricos y políticos constantes que dificultan otra clase de seguimiento de las hierofanias, sí existen determinados aspectos que al menos se pueden señalar resumidamente.

${ }^{5}$ Este problema, así como el de su contacto con las religiones griega y fenicia es el que pretendemos tratar próximamente.

${ }^{6} \mathrm{Cf}$. Brillante: (1986, pág) y nacimiento de la ciudad. 
Respecto a la sucesión cronológica, tras el Bronce reciente, del cual se conocen, por una parte, santuarios como los de Enkomi, abandonados con la ciudad, y por otra, los de Pafos y Kitión, que mantendrán una continuidad posterior ${ }^{7}$. De época geométrica, y generalmente adscritos a la fase final, tenemos los restos de Kitión (área de continuidad) una primera fase constructiva en Agia Irini, de la Acrópolis de Idalión, y de Agios Jakovos (sin mencionar una hipotetica en la acrópolis de Amatonte, todavia no se ha confirmado arqueológicamente, y la continuidad que se presupone en Pafos). Son esencialmente someros restos arquitectónicos con escaso material arqueológico.

En la época arcaica parece afirmarse una mayor divergencia entre los santuarios rurales ${ }^{8}$, por una parte, que conocen un auge parejo a un notable conservadurismo, y aquéllos de los principales centros urbanos, que se abren a nuevas influencias culturales exteriores de manera continuada. En este período ya hay evidencias de la mayor parte de los santuarios que mencionamos.

Para el estudio de estos santuarios, v.: O. MASson, 1973. Para un estudio ordenado cronológicamente de los períodos geométricos al clásico, podriamos tomar como referencia inicial el de E. GJERSTAD, 1948). En lo que se refiere al chipriota Tardio III. o Bronce Reciente III representa un momento de importantes novedades constructivas templares. $V$. Karageorghis (1982, págs. 101 y ss.) llama la atención sobre el hecho de que aunque éstas coinciden con la llegada de los primeros colonos aqueos, es sorprendente lo poco de su religión que han traido éstos con ellos del Egeo, excepción hecha de los "cuernos de consagración" como símbolo religioso (Mirtou- «Pigadhes", Kition y Palaepafos, y también en Pyla-«Kokkinokremos), aunque en Chipre es ligeramente diferente de los egens. Por otra parte, algunos elementos de la religión chipriota no serian extraños para los nuevos ocupantes, incluyendo el significado religioso del toro y ancla, por lo que se supone no tuvieron lugar cambios radicales. Este autor cree que, por el contrario, hay razones evidentes para pensar en una fusión gradual, teniendo en cuenta que a su llegada - de colonos aqueos-, la arquitectura religiosa en el Egeo no estaba tan desarrollada ni tan significativamente diferenciada. Por último, queremos hacernos eco de la opinión del arqueólogo chipriota respecto a la relación entre manifestaciones religiosas y metalurgia que se evidenciaría en varios santuarios de esta época.

${ }^{a}$ Los santuarios consisten a menudo en una pequeña cella, un altar y un patio mayor I dentro de un recinto mayor. El dios o dioses combinan varias cualidades: de la curación, atmosférico, bélico, fertilidad. Las ofrendas son esencialmente estatuas y estatuillas de piedra o, más frecuentemente, de terracota, además de pequeñas ofrendas como escarabajos, amuletos y objetos de bronce, estatuillas: figuras humanas, a menudo sosteniendo un animal o tañendo un instrumento musical para regocijo de la divinidad. Son sustitutos de los adoradores, y su presencia en el santuario es un recuerdo permanente al dios de su dádiva y ruego. Hay también figuras animales: usualmente toros y caballos, o jinetes, modelos de carros, etc. Las terracotas se construyen a partir de un cuerpo cilindrico a torno, con cabeza moldeada o modelada. Usualmente planas, sin decoración alguna, ésta puede aparecer con pintura negra u purpura. Estas figuras de terracota se colocarian en bancos alrededor del altar o sobre tablas de ofrendas en el patio del santuario (V., KaRAGEORGIS, 1982, pág. 140). 
Respecto a las influencias culturales, la griega parte de la fuerte presencia de elementos griegos y cretenses desde el Bronze Reciente, consolidada por los continuos contactos que se mantiene entre ambas, especialmente en el submicénico o primera fase del Geométrico. Como resultado de estos aportes se iniciaría un proceso de identificación entre las divinidades griegas y las preexistentes. Pero generalmente, se considera que la introducción de divinidades griegas se produce tardiamente, particularmente en época arcaica. La posibilidad de identificar un sustrato religioso griego que se superpusiese a otro indigena, o que conviviese con las creencias fenicias, se daria, primero, en relación con la profundidad de la influencia helena en época geométrica, y sopesando su permeabilidad en el mundo chipriota de aquel momento, y, a partir del siglo vi, con la nueva proyección de la cultura griega, que inunda las orillas del Mediterráneo, y en nuestra isla, terminará siendo muy importante con el helenismo, aunque sin anegar por completo a los otros elementos existentes. Así, la especial veneración que recibe Atenea en la vertiente noroeste de la isla (Soloi, Kakopetria, Mersinaki, Vouni) se entiende en relación con la influencia Atica, notable desde el siglo $v$ a.C. en ese área, pero sin obviar la presencia de un elemento fenicio que la asocia a Astarté, o incluso, eteochipriota, (V. Karageorghis, 1982, C. Bonnet, 1988).

El elemento fenicio, aparte de un hipotético sustrato de influencia oriental introducida en la Edad del Bronce, que lo apoyase, penetra su religión en la isla, emergiendo en numerosos lugares, y manifestándose con pujanza desde época arcaica. La documentación conservada nos habla del protagonismo que adquirió, asimilando sus divinidades con las griegas o las chipriotas preexistentes. Su proyección parece tener por epicentro a Kitión, internándose hacia el interior en abanico, en algunos casos, asociada a una expansión militar (Pyla, Golgoi, Idalion, Tamassos), para alcanzar incluso la costa norte (en Lapetos).

\section{ACHNA}

Un «témenos» próximo a la ciudad de Achna dio materiales datables entre las épocas Arcaica a Helenistica. Su problemática respecto al contexto arquitectónico es la misma que la planteada en el templo de Apolo en Tammassos ( $v$.), al que por otra parte se asemeja. El "témenos" consistía en un patio interior irregularmente oblongo, estrechándose en 
su parte meridional, y cerrado por un «peribolo" meridional de mampuestos. El acceso era una puerta a oriente frente a la que estaban dos estructuras rectangulares próximas entre sí, de barro y cubiertas con lajas, posiblemente altares. Otra estructura rectangular mayor, sólidamente construida, aunque pequeña quizás para ser una capilla, podría ser un cercado para un árbol sagrado (cf. Agia Irini) (E. Gjerstad, 1948, págs. 910).

\section{AGIA IRINI}

En la región de Paleokastro, en la costa oeste de la península de Kormakiti y próxima a la antigua Melabron, según la identificación propuesta por los arqueólogos italianos (L. Quilici, 1985, y P. E. Pecorella, y L. Rocchetti, 1985), tenemos el santuario de Agia Irini. Construido al final del Bronce reciente, estuvo en uso hasta el 500 a.C. aproximadamente. En la fase I del Cipriota Arcaico consistía en un "témenos" irregular rodeado por un "períbolos" o encintado de cascotes. En el centro se levantaba un altar sobre el que se situaba el símbolo cultural. Había una piedra oval plana, probablemente, una superviviencia del santuario de la Edad del Bronce (cf. el similar de Meniko). Podría ser considerado como la encarnación del poder de la fertilidad, aunque esta deidad está también simbolizada por el toro. Junto al altar existía una pequeña estructura de dos habitaciones rectangulares que se han identificado como recinto para los árboles sagrados. Hay también restos de estructuras de postes de madera que sostendrian probablemente los techados de dos cobertizos. Hay asi dos unidades separadas dentro del santuario, un patio abierto a un lado, y en un patio interior el otro, con el altar, abrigos y cercados para los árboles. En realidad, sigue el modelo de otros santuarios rústicos al aire libre más viejos de Vounous (cf. Vouni). (V. Karageorghis, 1982, págs. 141 y ss; E. Gjerstad, 1948, págs. 1, 3-4). V. Karageorghis (1977, págs. 13-14) ha supuesto que la divinidad aqui adorada estaba relacionada no sólo con la fertilidad, sino además, con el ganado y la guerra.

\section{AGIOS JAKOVOS}

Este santuario de época geométrica consiste solamente, frente a otros tipos de la misma época, en una capilla rectangular sin «témenos" 
ni altar, y aislada de cualquier asentamiento (E. Gjerstad, 1948, págs. 23).

\section{AMATONTE}

Amatonte, a $10 \mathrm{kms}$, al este de Limasol, es una ciudad que se ha considerado tradicionalmente como un caso claro de identidad cultural eteochipriota, pero, como matiza A. Hermary (1987, pág. 388), ésta hay que entenderla no como algo absolutamente uniforme, sino dentro de un contexto de convivencia de elementos de diferentes orígenes y tradiciones, que entran en juego en cada momento en proporciones determinadas. Algunos datos importantes, en efecto, se pueden valorar como señales de una autoctonia esencial: uso de una lengua no emparentada ni con el griego ni con el semítico, o las menciones de autores antiguos en las que se subraya su origen y enraizamiento chipriota. Pero si bien es cierto que la primera ocupación se remonta al siglo XI a.C., equiparable a la de Salamina, el poblamiento será escaso todavia, y no existen prácticamente restos de los períodos Geométricos I y II. Es sólo a partir del siglo vIII cuando se constata un auge marcado, debiendo sopesarse aqui la arribada de los fenicios a la isla en ese momento. El esplendor del reinado es todavia mayor en el siglo $\mathrm{v}$, posiblemente en relación con su actitud filopersa durante la revuelta jonia, lo que no es óbice para que su arte se impregne de helenismo.

A. Hermary comenta que quizás dentro de esa "refundación» fenicia se entienden las referencias de un culto a Adonis o Adonis Osiris, e igualmente, el nombre de "Malika" que según Hesiquios recibe el Heracles de Amatonte, resulta difícil no aproximarlo al fenicio "mlk", y a partir de ahi, sugerir una deformación del nombre "Melkart», o un teónimo formado, como el de Melkart, sobre el elemento «Mlk". Sin embargo, se conoce también en Amatonte gracias a una inscripción del siglo III a.C., un "Zeus Meilichios", de tal manera que la aportación del testimonio de Hesiquios permanece incierta (A. Hermary, 1987, pág. 384; C. Bonnet, 1988, pág. 336).

El principal santuario de Afrodita, divinidad que domina el panteón local, y a la que se le llama "Kypria", (es decir, diosa de Chipre) (Karageorghis, V., 1982, pág. 144), está en la Acrópolis. Esta identificación se considera segura por la inscripciones bilingües en eteochipriota y alfabé- 
tico griego del rey Androcles, en el siglo IV, a la "Diosa de Chipre" y a la "Afrodita de Chipre" (P. Aupert, A. Hermary, 1985, págs. 232 y ss.). Las referencias literarias que poseemos subrayan su antigüedad, y atribuyen su construcción al epónimo local ${ }^{9}$.

Aparte a referencias epigráficas a otras divinidades ${ }^{10}$, han parecido varias representaciones de Bes, destacándose la estatua colosal que ha sido objeto de varios estudios ${ }^{11}$.

\section{ARSOS}

Donde se han encontrado las famosas estatuas que representan a una mujer y un toro, tres de ellas dedicadas a la Afrodita de Golgoi (siglos vIl y vı a.C.) (O. Masson, 1960, J. Karageorghis, 1977, pág. 219).

\section{GOLGOI}

Los restos arqueológicos procedentes de un lugar al noreste de la moderna Athienou, y muy próxima a ella, se han identificado los de la antigua Golgoi, ciudad mencionada en las fuentes antiguas junto a Idalion en relación con el culto de Afrodita. En varias inscripciones de la isla se menciona en efecto a la "diosa de Golgoi" O "Golgiana" (11 bis).

${ }^{9}$ Sin embargo, no ha aparecido confirmación arqueológica del templo en época geométrica. Sobre las excavaciones francesas en la acrópolis: A. Hermary, 1988; M. Schmid, 1988

"Como "Theos Hypsios", o la de "siete entre las estelas".

- El Bes colosal de Amatonte, está realizado en un estilo arcaizante, pero el estudio estilístico ha confirmado una manufactura del 200 d.C. Serviria de fuente en una zona vecina al puerto antiguo. Representa probablemente una divinidad profiláctica y bienhechora, pero no estamos en condiciones de saber si corresponde o no a uno de los teónimos dados por los texto, por ejemplo, de Malika. Bes, presente en cualquier caso en Chipre desde el Bronce Reciente. donde ha podido jugar un papel en la elaboración de la iconografía heraclea de la leonté.

$"$ bis En las inscripciones silábicas procedentes de Idalión (ICS, 219) y Chrytori y en las dedicaciones alfabéticas de Arsos, al este de Goldoi y de Achna (O. Masson, 1971, pág. 331). 
O. Masson distingue tres lugares de proveniencia de los materiales: la citada ciudad antigua, una zona de necrópolis, y finalmente, bastante alejado en dirección este-sureste, el santuario de Agias Potios, donde han aparecido numerosas estatuas de Heracles y una interesante bajorrelieve de la segunda mitad del siglo vı a.C. que podria haber servido de base a una estatua colosal (O. Masson, 1971, pág. 326; C. Bonnet, 1988, pág. 331).

Otros documentos se refieren a un, al parecer, importante culto al "Gran Dios de Chipre», que se correspondería con Apolo, como se le denomina en otros documentos, o simplemente, «el dios» (te-o) ${ }^{12}$. Otra inscripción menciona a un dios llamado "Theos Hypsistos", que según el mismo O. Masson (1971, p. 331) debiera haber tenido un santuario en las proximidades de Golgoi.

\section{IDALION}

Situada a $22 \mathrm{kms}$. al noroeste de Kitión, al sur de la actual Dali, ocupada desde finales de la Edad del Bronce, fue capital de un antiguo reino, mencionada en un documento de época de Asarhaddon (hacia el $673-2$ a.C.). La presencia fenicia se confirma después del 470 , cuando es anexionada por Kitión con el apoyo persa, (C. Bonnet, 1988, pág. 328; Michaelidou-Nicolaou, 1986, pág. 335), pero algunos materiales de filiación fenicia se fechan en el siglo VIII a.C. Se componía de dos acrópolis, la occidental dedicada a Atenea, y la oriental, supuestamente a Afrodita. Entre las dos acrópolis se elevaba un "témenos" dedicado a Apolo. Los fenicios identificarian a Atenea con Anat y a Apolo con Resef.

La acrópolis oriental, de época arcaica, ha reportado terracotas y esculturas en piedra. La ausencia de inscripciones imposibilita empero confirmar qué divinidad era o se identificaba con ella, y apuntan tan sólo hacia una divinidad femenina (E. Gjerstad, 1948, pág. 7). El "témenos" consistiría en un patio abierto, con pórticos en sus lados sur y oeste.

En la "occidental", el "témenos de Atenea" o Anat, tiene una primera fase en época geométrica. Estaba rodeado por un muro con fines

12 Sobre el culto de Apolo de Golgoi: O. MASSON, 1966, págs. 22-31; M. YON, 1986, pág. 143, sobre la dificultad de interpretar la iconografia. 
defensivos, que servia además como "peribolos" del "témenos». Era de adobes en tres formatos diferentes, sobre cimientos de piedra. En la parte occidental del recinto se han localizados las estructuras de una capilla con frente abierto, construida con paredes de estilo idéntico al encintado general, pero de menor espesor, y un altar. Parece que en la época arcaica posterior un área alrededor del altar se cercó con un frágil muro, formando un patio interior separado del resto del "témenos", del que apenas quedan restos. En el complejo se realizaron sucesivas reconstrucciones en época arcaica, y se erigieron numerosos santuarios en el lugar del antiguo (E. Gjerstad, 1948, págs, 2, 5 y ss.).

Del "santuario de Apolo" las referencias son más escasas. Parece posible distinguir entre dos grupos de edificios, orientados en direcciones diferentes, en uno de los cuales se aprecian semejanzas con el santuario de Afrodita.

En suma, las inscripciones permiten distinguir dos cultos esenciales, el de Anat-Atenea, y el de Resef, atestado a partir del siglo IV a.C. y equivalente o interpretado en Apolo Amyclaios.

Para C. Bonnet (C. Bonnet, 1988, pág. 326) el interés de este sitio radicarian en mostrar como una iconografía heraclea se ha podido implantar en un santuario consagrado, según toda evidencia, a Resef (h)mkl. La génesis de este nombre y sus relaciones, por una parte con el dios Mekal (o Mekar, si el signo egipcio puede tener dos valores) de Beth Sahn, del II milenio, por otra, con el Apolo de Amyclea, en Laconia, ha originado toda una literatura sin que el problema encuentre una solución hasta el momento satisfactoria para todos. Mekal (MKL) aparece en Kitión en la famosa inscripción del santuario de Astarté, pero no es seguro que se trate de un teónimo. En cualquier caso no se le encuentra ninguna relación con Melkart.

\section{KAKOPETRIA}

C. Bonnet, a quien seguimos aquí, hace referencia al sitio de Kakopetria, al noroeste de Salamina, como lugar de procedencia de fragmentos de estatuas heracleas, comparables a las de Kitión e Idalión. Habrian sido exhumadas por J. L. Myres en 1913, quien exploró el sitio después de unos descubrimientos fortuitos. Saldrian a la luz así las ruinas de un "Santuario" activo entre los siglos VII al IV a.C. Además de Heracles, 
aparecerían restos del Zeus Ammon, el dios cornudo sedente. En cualquier caso, esta autora considera imposible dar una adscripción (C. Bonnet, 1988, pág. 332).

En Ayialadhes, lugar aislado de la vertiente septentrional de las montañas de Troodos, al sur de Kakopetria, se encontró un depósito de terracotas o "favissa". Por lo que sabemos de ellos, se supone que pudo pertenecer a un santuario que, por los materiales exhumados, sería de Atenea (especialmente numerosas son las representaciones de esta diosa con su escudo y lanza). Es significativa la presencia de cuatro figurillas de Heracles con leonte, repitiendo una asociación que ya existía en el Atica, aspecto que señala Bonnet en relación con la influencia ateniense en esta región, y la fuerte implantación de Atenena en ella (como en Vouni) hechos quizás no fortuitos ni independientes (V. Karageorghis, 1977 b, V. Karageorghis, 1982, 161-2).

\section{KAZAFANI}

Al norte de Potamia y cerca de Idalión, pertenece a la II fase del arcaido, el hallazgo de una "favissa" con materiales comprendidos entre los siglos VII o VI a.C. ha dado, entre otros múltiples objetos, figurillas del tipo de Astarté, y una estatuilla de Hermes. Dentro de este material escultórico sería reseñable su carácter marcadamente chipriota, y se ha supuesto que podría proceder de un santuario de Heracles-Melkart, en base a la representación del héroe en una pieza extrangulado el león $\mathrm{V}$, (Karageorghis, 1978; id. 1982, pág. 150).

\section{KITIÓN}

Kitión, actual Larnaka, la romana Citium, ha sido un lugar de ocupación continuada desde el Bronce Reciente III o Chipriota Reciente III. Parece clara su conexión con el centro metalúrgico de Hala Sultan Tekke en los siglo XV-XIV a.C. En el siglo XIII, como Enkomi, es un lugar fortificado. Comprende varios lugares, intramuros y extramuros (en las exca- 
vaciones actuales se les ha dado a algunos un ordinal de área correspondiente).

KATHARI.: (Área II) según su excavador, V. Karageorgis, sería ocupado sin discontinuidad desde la edad del Bronce Reciente (finales del siglo XIII o inicios del XII (hacia 1190 a.C.), y tendría una función religiosa e industrial. Para V. Karageorghis, la presencia de aqueos explicaría la reorganización y la presencia de cerámica micénica III C (Bonnet, 1988, pág. 316): reorganización:

El conjunto templar comprendería 5 templos. El 1 y 2 formarian un primer complejo, junto con un "témenos" abierto. El templo 1 se supone dedicado a una divinidad femenina, aunque no se ha encontrado en él estatua alguna (Karageorghis, V., 1982, pág. 123) y tradicionalmente se le denomina "de Astarté». Abandonado hacia el 1000 a.C., con la llegada de los fenicios, en el Geométrico III, se levanta sobre sus cimientos un nuevo templo, que mantiene las dimensiones del anterior, pero con nueva distribución interior. El mobiliario de época arcaica cuestiona quizás esta atribución. Bucraneos, que habrían servido para ritos enmascarados, atestiguados en Chipre en época del Bronce Reciente, y dos figurillas de Bronce que evocan el tipo de Bes, parecen más propios de divinidades masculinas (A. Caubet, 1987, pág. 160, se remite al trabajo de M. Yon: (1986) sobre la interpretación chipriota de las divinidades masculinas, para señalar que algunos de las posibles contaminaciones del carácter de Bes podría acercarse, de forma grotesca y envejecida, a la del Esmoun juvenil). Finalmente, en época arcaica, a partir de tres incripciones a Melkart, Eshmoun-Melkart, y a un Baal de Kition, quizás alusiva también a Melkart, sobre vasos procedentes de un «Bothros", se ha hipotetizado un culto a Esmoun-Melkart o Melkart desde el siglo IX, en paralelismo con el sitio de «Batsalos».

Un segundo complejo más modesto comprendería los templos 4 y 5 : construidos próximos, separados sólo por una calle. También remotaria el Bronce Reciente, y de ésta época proceden una serie de hallazgos, como una pipa de marfil para fumar opio, del sancta-sanctorum del templo 4 , además de una pláca de marfil con una representación de Bes, similar a tipos palestinos ${ }^{13}$. No se conoce a qué divinidad se consagraba, pero una terracota femenina de la Hierro Temprano (Geométrico). En época arcaica aparecen imágenes de portadoras de ofrendas, o de "diosas desnudas» (Caubet, 1986 pág. 159).

\footnotetext{
13 KaRAgeorgis anota que la práctica de fumar opio con fines medicinales es conocida en la Antigüedad.
} 
El templo 5 correspondería a una divinidad masculina, quizás a un "Baal de los navegantes". Se han encontrado cráneos de toro en el suelo, que servirian como máscaras antropomorfas de terracota en un depósito («bothros») Son máscaras similares a las que se encuentran en Hazor y Tel Qasile, en Palestina. Figuras de terracota de jinetes de época posterior, lo que podrá ser una indicación del culto a una divinidad masculina páredro de la femenina del templo 4. (Karageorgis, p. 105, 123).

CHRYSOPOLITISSA.: (Área I) situada frente al área anterior, su ocupación sin embargo es intermitente desde el Bronce Reciente. Sería un barrio residencial y artesanal. De este sitio proceden fragmentos de estatuas masculinas de época arcaica, dos miniaturas de altares, y otras figurillas similares a las de Kitión-“Bamboula" (Caubet, 1986, pág. 161).

BAMBOULA.: donde se encuentra un complejo a partir del siglo $\mathrm{XI}$ a.C. que va sufriendo varias elaboraciones y modificaciones. Hacia el 500 a.C., parece que se rendía culto a una divinidad representada bajo los rasgos de Heracles, y que continuaba el culto a una diosa femenina, de la que habrían llegado restos de épocas anteriores sin contexto arqueológico, tales como cabezas de Hathor, y fragmentos de figuras femeninas con los brazos en alto, que indican una continuidad en el culto a la diosa además. Después se ha sugerido que estuviese dedicado a un predecesor de Heracles-Melkart.

Según Caubet, el análisis del complejo sagrado de Kitión-Bamboula parece mostrar la coexistencia de dos zonas distintas, cuyo emplazamiento y disposición evolucionan con el curso del tiempo, desde los siglos IX al IV, separadas por un muro desde época arcaica. Una divinidad masculina ocuparía el área norte y oeste. A ella corresponderían unas estatuas procedentes de un "bothros", que quizás se tratasen de Resef. Al otro lado seria una divinidad femenina, en época arcaica representada como "diosa desnuda", en el siglo vi como Hathor, y denominada Astarte en referencias del siglo $v$ y IV. Curiosamente, esta protectora de una dinastía fenicia adoptaria una figuración griega. A su culto se asocian las construciones hidráulicas, usadas en supuestos ritos bajo su advocación.

C. Bonnet (1988, pág. 320) en base a la hipótesis de una identificación de las estatuas heracleas griegas procedentes del "bothros" fechado hacia el 500 a.C. con Melkart, señala la importancia de este santuario como lugar donde se produce la primera asimilación entre Melkart y Heracles. Para ella la estatua de Zeus con el "fulmen" y en posición de combate del siglo vi a.C., podría explicarse como otra manera de representar al "Baal de Kitión", equivalente con un "gran dios" local. 
Distintos argumentos apoyarian la asociación de este Baal con Melkart: testimoniado en Batsalos, en el entidad kitiona, su carácter políado, su conexión con los ritos del fuego y el agua; su asociación de Astarté, son una serie de aspectos rastreados un poco por todo el Mediterráneo y que reproduce el modelo cultural tirio.

KAMELARGA: supone el último lugar dentro del perímetro mismo de Kitión donde se encuentran restos arquitectónicos y figurillas de terracota, del mismo estilo arcaico, esta vez con afinidades iconográficas de cultos de la costa fenicia, de una "diosa grávida" de tipo finicio. (Caubet, 1986, 161, E. Gjerstad, 1948, pág. 10).

A partir de ahora, los santuarios mencionados de Kitión son extramuros.

ANEROMENI a proporcionado unos fragmentos de esculturas del siglo $v i$ en una fosa de ofrendas, y una inscripción a una divinidad femenina.

SANTUARIO DE ARTEMIS PARALIA también llamado "Las Salinas", santuario que ocupa una colina al noreste del lago salado, a unos 400 metros del anterior, es el origen de una serie de materiales de época mayoritariamente clásica (siglos $\vee$ y IV a.C.), es decir, del momento más floreciente del reino de Kitión, y de sabor absolutamente griego. Son terracotas que representan a una diosa entronada y con "calathos", tanto sola como acompañada de un paredro. Podría tratarse tanto de Afrodita como de Deméter y Coré, Artemis, etc. Su nombre procede de las inscripciones griegas de época romana que mencionan a esta divinidad. (A. Caubet, 1986, pág. 164-6).

BATSALOS es otra colina que ha proporcionado inscripciones y restos arquitectónicos, los cuales han llevado a suponer la existencia de un pequeño santuario a Eshmoun-Melkart. La primera fundación podria ser, como hipótesis, a Eshmoun (C. Bonnet, 1988, pág. 326).

\section{KOURION}

El "santuario de Apolo Hylates" dista kilómetros y medio de la antigua ciudad, dominando la bahía de la moderna Episkopi. Consistía en un complejo de elementos que se fueron añadiendo con el tiempo, a partir de un simple altar al aire libre. El lugar se fue transformando progresiva- 
mente desde su rústica simplicidad, a partir de la primera monumentalización en época arcaica. Material cerámico y terracotas datadas entre el 800 y el siglo vi proceden del primer templo ${ }^{14}$ y de un particular edificio circular descubierto en las últimas excavaciones, fechado también en época arcaica ${ }^{15}$. Una ampliación posterior al 550 a.C. incluyó la calzada principal, un cercado al oeste con el mencionado edificio circular. y posiblemente, algunas canalizaciones excavadas en la roca. El material fechable a finales del siglo Iv indica una mayor actividad. Los añadidos continuaron en época helenística, augustea, neroniana y trajanea, sin alterar en principio la organización esencial, alrededor de la cual se suponen unos rituales y recorridos para peregrinos que visitaban el santuario (D. Soren, 1973).

\section{LAPETOS}

Situada en la costa septentrional y al noreste de la actual ciudad de Lapitos, es un lugar donde se documenta en época Geométrica la convivencia entre chipriotas y una población griega cuyos antecedentes serian micénicos. De ella proceden también monedas acuñadas por reyes griegos con inscripciones en fenicio, documento excepcional de una convivencia sobre la que habrá que profundizar. Del entorno de esta localidad provienen una serie de figurillas en terracota femeninas, de un tipo muy común en la isla, que ha llevado a cuestionar la posibilidad de un culto a una divinidad femenina (M. Yon, y A. Caubet, 1988). MichaelidouNicolaou (1. Michaelidou-Nicolaou, 1987, pág. 337) señala que, sin embargo, no aparecen inscripciones fenicias ni en silabario chipriota en la misma ciudad, sino que provienen del santuario de LARNACA-TES-LAPETOS, antiguamente Narnaka, lugar más modesto que se encuentra más allá de las montañas, en dirección sudoeste. Éste sería un pequeño habitat rodeado de uno o varios templos y dependiente de la ciudad de Lapetos, unida a ella por un camino que recorrían supuestas procesiones.

$14 \mathrm{Cf}$. las observaciones hechas por E. Gjerstad sobre las particularidades del estilo arcaico usado: 1948, pág. 12; sobre el depósito y ofrendas más antiguas del santuario, $v$. V. KARAGEORGHIS, 1982, págs. 142 y ss.).

15 Soren (1973) hipotetiza sobre la posibilidad de que cobijase un centro de un culto apolíneo relacionado con el árbol. 
Las inscripciones procedentes de este entorno (dos fenicias, una bilingüe feno-griega y otra griega alfabética) mencionan, una, a Melkart, Osiris, Astarté y los dioses de Biblos. El primero se localizaría en el sitio de Larnaka, mientras que los restantes lo serian en Lapetos. Una segunda se refiere también a Melkart y a una ofrenda realizada en su santuario, pero no da indicación sobre su localización. Una tercera habla de un Poseidón Narnakios ${ }^{16}$, es decir, con un topónimo que recibía entonces Larnaca-tes-Lapetos. Una cuarta, finalmente, se dedica a Anat-Atenea. (C. Bonnet, 1988, págs. 333-4, J. C. Greenfiel, 1987).

\section{LIMASOL}

"LIMASOL-KOMISSARIATO" es un hallazgo consistente en una pequeña cella semicircular descubierta dentro del casco urbano de Limasol, y datada en el 500 a. C., donde se encontraron numerosos materiales. No se puede asegurar si esta cella estaba asociada con el muro delimitador del "témenos" o "períbolo". El carácter de las ofrendas votivas ayudan a identificar la divinidad adorada en este santuario: protectora de la fertilidad, esencialmente masculina. Se encontró un falo de arcilla en la parte central de la cella, asi como figuras de toro con prominentes genitales. También se encontraron algunas figurillas femeninas, quizás la compañera femenina del dios. En el momento de su publicación se dio la noticia también de evidencias de otro santuario, con figuras en terracota con brazos en alto, presumiblemente del siglo XI, dos de ellas del tipo de "capana", a torno, análoga a las submicénicas asociadas a la diosa madre, vasos zoomorfos, un modelo de navio y cerámicas. Además, aparecia por debajo de este hallazgo material del chipriota Tardio I y II (V., Karageorgis, 1982, pág. 150, y V., Karageorgis, 1977, págs. 645).

16 Se ha emitido la hipótesis de una identificación entre Poseidón Narnakios y el Melkart de Larnaka. Relaciones de Melkart con la navegación, a menudo ilustrada, sería efectivamente favorable a esta identificación. Interés de esta hipótesis es la de proponer un caso de "interpretatio" alternativo de Melkart, hasta el presente siempre asimilado a Heracles. 


\section{MENIKO}

Al oeste de Nicosia y perteneciente a la etapa final del período arcaico chipriota, es notable por la buena conservación de sus restos arquitectónicos y el carácter inusual de los objetos que contenía. Estaba situado en un área agrícola. En su segundo periodo constructivo, consiste en dos unidades arquitectónicas, paralelas y separadas por una escalera. La primera y mayor de ellas comprende un patio abierto con una escalera que conduce desde el patio a otro interior con una cella al fondo, esta última posiblemente techada, y con un cercado que podría haber sido para un árbol sagrado. De su cella procede una representación de Baal Hammon sedente, barbado, y con cuernos de carnero, y dos tymateria. V. Karageorghis (1977, págs. 44-5) considera a esta figura especialmente importante, y la compara con el dios-carnero libio conocida como Ammon, comentando la posibilidad de que su culto haya sido introducido desde Cirene, ciudad con la que el rey Evelton de Salamis mantuvo relaciones especialmente amistosas a mediados del siglo vi a.C. También en Cartago se adoraba a una "Baal-Hamman", señor del altar perfumado ("hammanim»), asociado por tanto a los tymateria (también documentados en Meniko) y en compañia de una diosa. Todo ello apunta, por una parte, a un posible carácter fenicio, ligado a una búsqueda de cobre en la región, pero sin excluir, más bien al contrario, una divinidad indígena de raíz prehistórica. Algunas terracotas de figuras humanas se han hallado junto a las de toros.

La segunda unidad arquitectónica está el este de la primera, y consiste en dos habitaciones restangulares, el acceso a una de las cuales se hace por una escalera (V. Karageorgis, 1982, págs. 144-50).

\section{MERSINAKI}

En esta localidad entre Vouni (v.) y Soloi (v.) se constantan materiales del siglo $v$ en el templo de Lykios Apolo, donde se veneraba a Atena (V. Karageorghis, 1982, pág. 162). 


\section{PAFOS. (PALAIPAPHOS)}

Pafos es el centro principal del culto griego de la Afrodita chipriota. Aquí no se la menciona por su nombre, sino como "Anassa": la señora (V., Karageorghis, 1982, pág. 144). Pafos, la ciudad originaria, llamada posteriormente Palaepafos, estaba donde hoy se situa la ciudad de Kouklia, sobre una colina que domina el Diarrizos, y a unos dos $\mathrm{kms}$. del mar. En la Odisea se menciona a un rey Kinyaras de Pafos, y también se la encuentra en documentación de la época de Asardadon.

El celebérrimo santuario de Afrodita y su gran templo han dejado algunos vestigios al suroeste de Kouklia. El fue sin duda un importante factor en la continuidad de la ciudad, manteniendo su importancia como lugar de culto, cuyo prestigio se reconoce en toda la isla y en el mundo griego ${ }^{17}$. Es, junto con Kitión, uno de los santuarios que conserban una continuidad desde la Edad del Bronce. En realidad, el lugar se habitó desde el calcolítico, y la presencia micénica se confirma por cerámicas ( $V$., Karageorghis, 1965, págs. 157-84). Las excavaciones han evidenciado que la primera arquitectura monumental procede del 1200 , pero su planta y alzado no puede reconstruirse con precisión, ya que estas estructuras sufrieron mucho a lo largo de los siglos siguientes, pero se aprecia un "témenos" abierto, con otro menor y cubierto, que sería el "sancta-sanctorum", usando un esquema no muy alejado de otros del Cercano Oriente, y al de Kitión. Además de las trazas del templo, se han constatado cuernos de consagración (Maier, 1975, págs. 77-9). Permanece abierta la cuestión de si la construcción del primer santuario monumental estaria conectada ya con la llegada de los primeros griegos a Palaepafos, o si la influencia egea sobre el culto fue posterior, ya que junto a las figurillas femeninas de tipo cretense, se constatan otras anteriores (F. G. Maier, M. L. Wartburg, v. 1985, págs. 149-50). El santuario se compondria de un gran "témenos" rectangular con una entrada monumental, rodeado por una "stoa" y edificios diversos. Tras su destrucción por un terremoto, fue reconstruido en época romana, erigiéndose al sur una nueva stoa. Algunas representaciones sobre monedas lo muestran con una naos dividida en tres partes, y precedido de un patio; dos columnas encuadrarían la entrada al "sancta sanctorum».

17 J. Karageorgis, 1977, pág. 197, recoge la mención de Estrabón, de que cada año todos los hombres y mujeres de Chipre iban a Pafos, haciendo el camino de Pafos a Palaefafos y hasta el santuario. 
Tras la revuelta jonia, la ciudad fue asaltada por los persas. Los restos de la batalla, que han podido ser documentados arqueológicamente, han proporcionado también vestigios (capiteles jónicos, esculturas en caliza, "kouroi", inscripciones del siglo vi y ornamentos arquitectónicos diversos) de un "santuaro arcaico» que se elevaría no lejos de alli, y que habría sido demolido por los persas para utilizar sus piedras en la construcción de la rampa de ataque, (F. G. Maier, M. L. Wartburg, v., 1985, p. 157).

PAFOS. (NEAPAPHOS)

Hacia el fin del siglo Iv a.C., esta ciudad fue edificada cerca de la ciudad actual de Katopaphos, para reemplazar a la primera ciudad de Pafos, aproximadamente a $16 \mathrm{~km}$ al sudeste, y servir de capital y centro administrativo. En el siglo $\|$ a.C. suplanta a Salamis en este papel.

Al este de la ciudad puede identificarse el "templo de Apolo Hylates", subterráneo y excavado en la roca. Comprendía dos piezas: la del fondo circular techada en forma de cúpula, y la anterior rectangular. Algunas inscripciones indican que este santuario habria sido excavado en el siglo Iv a.C. Al norte de la ciudad, y datado en la misma época, se encuentran otras cámaras subterráneas unidas por pasajes abovedados, y que quizás formasen parte de otro santuario, porque estaban totalmente entornados por muros (J. Mlynarczyk, 1986).

J. Poilloux (J. Pouilloux, 1973, pág. 412), a propósito de su estudio sobre la Artemis Paralia de Kitión, comenta el hecho de que cuando el rey y sacerdote de Afrodita, Nicocles, traslada la ciudad, define un "santuario de Artemis Agrotera" ${ }^{18}$.

${ }^{18}$ En la casa de Dionisios, del siglo 111 d.C. se han encontrado numerosos materiales entre los que aparecen figuraciones de Bes, Isis, Harpócrates, y de un personaje vestido con una corta túnica. El hecho de que vaya armado con un bipenne y de arco, y pose el pie sobre un león le asemeja a representaciones encontradas en Fenicia y en Cartago. La posibilidad de asimilarlo con Melkart se daria en la medida en que este se sincretiza previamente con Nergal, lo cual puede afirmarse sin dificultad. 


\section{POTAMIA}

En un depósito de al noreste de Dhali (antigua Idalión) se han recuperado un sustancioso número de estatuas, masculinas todas excepto dos. Entre ellas destacan un torso de Heracles, Apolo tocado la lira, atletas desnudos y un guerrero cubierto con casco, etc. y un grupo de "Opaon Melanthios". Algunos detalles, como el elevado número de cabezas coronadas de jóvenes y atletas, han sugerido a $V$. Karageorghis que se tratase de un "bothros" de un templo a Apolo, cuyo aspecto como protector del ganado está en consonancia también con las estatuas de "Opaon Melanthios". ¿Estariamos ante un segundo gran santuario a Apolo, junto con el de Apolo Hylates en Kourión? La estatua de Heracles no seria impedimento para esta hipótesis, teniendo en cuenta que es un hecho constatado generalmente, como la presencia de estatuas de diferentes divinidades en santuarios consagrados aparentemente a una divinidad, argumenta Karageorghis (V. Karageorghis, 1979).

\section{PYLA}

En la proximidad septentrional de Kitión, este lugar recibió fuertes influencias de aquél, principal bastión fenicio chipriota. En él se adoraba a Apolo bajo los nombres de "Mageirios" y "Lakeutes" (conectado con los sacrificios y la adivinación) (V., Karageorgis, 1982, pág. 144).

\section{SALAMINA}

Habitualmente se reconoce a Salamina como sucesora de Enkomi, que está en su inmediata proximidad, hacia el oeste. Un terremoto habría motivado el traslado, que se realizaria de manera progresiva, en el período de una generación, a partir del 1075 a.C., hacia la nueva localización que domina la magnífica bahía, acorde con las aspiraciones marítimas griegas. La tradición épica griega atribuye la fundación de su 
ciudad a Teucros, que fundaría también el "templo de Zeus Olímpico» y sería su primer sacerdote. De este templo, tan famoso como el de Afródita en Pafos, no se han encontrado restos. M. Yon comenta al respecto la existencia de un santuario anónimo, sin advocación precisa, fundado en el siglo XI a.C. y activo hasta la epoca arcaica, situado en la parte oriental del recinto de la ciudad. Esta autora asocia materiales como figurillas y pequeños prótomos que reproducen máscaras de toros, símbolos de este animal comunes en Chipre y otros lugares del Mediterráneo oriental desde el II milenio y presuntamente usados en ceremonias, con el gran dios que asume la fuerza vital y la fertilidad de los campos, y que en época clásica se convertiría en el Zeus griego. En época arcaica el santuario se abandona, y faltan testimonios de época clásica para ubicar la continuación del viejo lugar sagrado, aunque sin duda el culto continuó en el siglo v. La influencia egipcia, por otra parte, ayudaría a una transformación iconográfica, y quizás se representase a Zeus en los siglos $\mathrm{VI}$ o $v$ con cuernos de carnero, asimilado a Baal-Ammon (M. , Yon, 1985).

Con la ampliación urbanística de la ciudad en época ptolemaica, se emprende la construcción del nuevo templo, precedido de una explanada monumental, y cuya construcción se alarga hasta época romana. Este gran templo corintio que se levantaba al sur de la ciudad, junto al ágora, con cella cuadrada al sur, y un reservorio construido en el reinado de Septimio Severo, ¿fue sucesor de aquél otro legendario?

Por otra parte, el culto a Afrodita, que algunos textos mencionan como señora o soberana de Salamina, ha sido estudiado por Jacqueline Karageorghis (1980, págs. 203-14), quien a partir de esta referencia analiza el material arqueológico pertinente. Aparte de materiales procedentes de contextos funerarios ${ }^{19}$, dentro del recinto de la ciudad se han descubierto numerosas figurillas que llevan a supone la existencia de un santuario intramuros, consagrado en los siglos $v$ y IV a.C., sino antes, al culto de la divinidad femenina polivalente, quizás diferenciable en varias del panteón griego ${ }^{20}$. Esta divinidad podría ser similar a la que se veneraria

19 Tan tempranos como el siglo xI, en la tumba I de Salamina, donde aparece una figura botelliforme similar a las diosas cretenses, pero también a las chipriotas, de significado posiblemente religioso. Después de muchos siglos oscuros, las tumbas reales de Salamina producen objetos ornados con representaciones de diosas desnudas con las manos en los senos o sosteniendo unos animales.

${ }^{20} \mathrm{Cf}$. esta hipotesis de J. Karageorghis con la de M. Yon (1985) quien atribuye -entre interrogantes- los materiales a un santuario de Artemis en las proximidades del mencionado templo, junto al recinto meridional. Se apoya en la posible existencia de animales entre las terracotas - una cierva, quizás - similares a las de Achna o al santuario próximo al lago salado en Kitón, y en la proximidad del emplazamiento al mar y al puerto, que 
en un santuario rural, próximo al monasterio de San Bernabé, del que se conoce un depósito votivo ("favissa" o "bothroi") de donde proceden numerosas ofrendas de estatuas calcáreas representando a la divinidad o a sus fieles con diferentes atributos.

Esta autora aventura que al trasladarse desde Enkomi, sus habitantes portarian sus divinidades consigo. En el último santuario de Enkomi, el de los "Centauros", se recuperaron numerosas figurillas pintadas con los brazos elevados, femeninas la mayoría (J. C. Courtois, 1971). Precisamente se documenta entonces, hacia los siglos $X I-x \mid$ a.C. una divinidad femenina en esta ciudad ${ }^{21}$ que se añade a las masculinas que ya conocemos.

\section{SOLI}

Situado en la costa noroeste isla, en un lugar hoy llamado Potamos tou Kamboua, y en la proximidad de Vouni, era un importante enclave filoheleno ${ }^{22}$. Poseía un puerto, una ciudad baja y una acrópolis. En la acrópolis se distinguen los escasos restos de un "santuario", casi totalmente destruido. E. Gjerstad observaba que, debido a la imposibilidad de distinguir una puerta, su orientación no era clara. Probablemente se trataba de un templo «in antis», con pronaos, cela y "opistodomos» o "adyton", pero se plantea la posibilidad de que se pueda reconstruir como un templo de tipo chipriota, con tres cellas contiguas, abiertas a un patio al norte del edificio. Otros fragmentos dóricos, como parte de un entablamento, son probablemente arcaicos. De época clásica se conservaron restos de un friso de mármol decorado con escenas representando una

invitarían a sugerir un santuario de Artémis Paralia, conocido en Salamina por una inscripción.

${ }^{21}$ Figuras femeninas, algunas con diadema, algunas otras de gran talla, presentan numerosas semejanzas con figuras cretenses subminoicas, por lo que no puede dejar de testimoniar un aporte griego real: se ha pensado efectivamente que cretenses se habrian instalado en Chipre en el siglo xi llevando con ellos la diosa de los brazos elevados, la Gran Madre cretense (J. KaRAGEORGHIS, 1980, págs. 203-14).

${ }^{22}$ Los intereses griegos en esta región rica en mineral se perciben tangencialmente en la leyenda qué protagoniza Solón, el reformador político ateniense, quien aconsejo al rey de Aipeia (ciudad vecina) instalarse en aquel lugar donde encontrarian yacimientos importantes de cobre. En compensación por tan apreciable indicación la ciudad tomaria su nombre. 
amazonomaquia, indicando la existencia de un edificio de estilo jónico (Gjerstad, 1948, pág. 17).

\section{TAMASSOS}

Tamassos se considera por algunos una ciudad de origen prehelénico, afirmación que apoyan en su etimología, conectada con la de las ciudades de la Edad del Bronce de Asia Menor y Grecia. Situada en una región rica en minas de cobre explotadas desde la protohistoria, la tradición griega la considera una colonia fenicia, pero esta implatación fenicia es tardia: hacia el inicio de la edad del Hierro. Quizás se menciona en un prisma de Asardadon (hacia el 680-69) bajo el nombre de Tamesu. De ella subsisten varias ruinas en la actual ciudad de Politiko, sobre la orilla derecha del Pedaios.

El supuesto emplazamiento del "templo de Apolo», al noroeste de la ciudad, fue excavado en el siglo pasado. Estaba dentro de los límites de la antigua Tamassos, en la actual localidad de Frangissa. E. Gjerstad planteaba la dificultad de reconocer el trazado del antiguo "témenos" frente a otras reconstrucciones posteriores, por lo que en última instancia, el "témenos" arcaico original habrá de asociarse a los restos arquitectónicos conservados de esa época. Por lo que se puede distinguir, era un pequeño patio trapezoidal con un pequeño nicho y un corredor de acceso "angular» hacia el sur. El nicho rectangular al exterior y cóncabo al interior, conservaba todavía "ex votos» escultóricos «in situ». Sin embargo es posible que todo ello estuviese incluido en un área mayor. A través de las esculturas podemos datarlo en la época arcaica (E. Gjerstad, 1948, pág. 9).

Las nuevas excavaciones de expedición alemana de J. G. Buchholz, han recogido una cabeza hathórica que testimonia la influencia egipcia.

Los hallazgos se han realizado sobre todo en los recintos de época arcaica y helénica, y sobre el "templo de Afrodita". De sus numerosos «bothroi" o fosas sagradas se han recuperado cenizas mezcladas con osamentas, lámparas, figurillas de terracota, cerámicas, etc. todo ello remontable a la época arcaica. Los objetos votivos más antiguos datan de los siglos VII a.C. Otro altar se ha hallado al oeste, rodeado de ofrendas votivas. Consisten en un enorme bloque de piedra provisto de una base central, o mesa de ofrendas rodeada de 18 cúpulas. Podría estar consa- 
grado a la "Madre de los dioses", como parecen indicar el nombre de esta diosa en una inscripción encontrada el siglo pasado en la vencidad, y una estatuilla de Cibeles sobre los dos leones. Al oeste se encontraba el barrio industrial, donde se trabajaba el cobre. El estudio estratigráfico del templo, encerrado en un muro que constituia el "témenos", ha permitido constatar una primera destrucción hacia la revuelta jonia contra los persas, en el 499-98 a.C., y una segunda bajo el reino de Ptolomeo I. (cf: O. Masson, 1968, y O. Masson, 1964; H. G. Buchholz, 1972, H. G. Buchholz, 1973, H. G. Buchholz, 1974, I. Michaelidou-Nicolaou, 1987, pág. 337): inscriciones muestran que los fenicios adaptaron sus divinidades a las locales.

\section{VONI}

Próximo a la localidad de Voni, un "témenos" dedicado a Apolo con esculturas datables entre los periodos arcaico al helenístico. Salvadas las distancias de los lejos que están lo conservado de lo que fue la parte excavada nos muestra una porción de "témemos" con muro de mampuesto, pero de planta más regular que los anteriores. Tres columnas «in situ» de probable estilo dórico y quizás para soportar el techado de un portico. (E. Gjerstad, 1948, pág. 10).

\section{VOUNI}

La erección del complejo palacial del Vouni, sobre un eminente promontorio rocoso en la costa noroeste de la isla, tuvo por finalidad controlar la vecina ciudad de filogriega de Soloi, a unos $7 \mathrm{kms}$ al este.

El rey Stasioicos de Marion, propersa, albergó allí una guarnición. Ello nos ha proporcionado un caso único de un palacio real fortificado del siglo $v$ a.C. Su construcción fue realizada en dos etapas, del 500 al 450 a.C. y del 450 al 380 a.C. aproximadamente. En la parte sur de la roca, la más elevada, se alzaba un templo a Atenea, y la parte norte, formada por terrazas, la ocupaba el palacio propiamente dicho. Éste se componía 
de estancias, baños y almacenes, pero además, de un variado y relativamente numeroso conjunto de capillas, aisladas o con patios.

Tras la victoria sobre los persas de Kimón, se hizo una redistribución del palacio, para formar un edificio tipo mégaron (V. Karageorgis, 1982, pág. 161).

El "templo de Atenea" data de la primera fase de la construcción, y ocupa, como hemos dicho, la parte más alta. Consistía en un amplio patio con una cella al fondo. Una cella cuadrada se le añadió más tarde. Junto a la entrada del patio, una serie de habitaciones albergaban las ofrendas, evocando la moda de los "tesoros" griegos, como en Delfos. Una de las ofrendas halladas en esta parte del santuario es una vaca de bronce, pretendida copia de una famosa obra de Mirón. Entre otras ofrendas, están la estatua de Atenea con casco corintio, así como muchos altorrelieves en el que se representa un toro atacado por dos leones.

\section{VOURNES}

G. Cadogan (G. Cadogan, 1985) a propósito de la breve reseña de sus trabajos en Maroni, (distrito de Larnaca), lugar con una historia de antiguos asentamientos, describe el sitio de "Vournes" y sus antecedentes en el Chipriota Tardío I y II, momento en que se levantaría un edificio de silleria, de los primeros de la isla (inicios del siglo XIII, es decir, Chipriota Tardio || C) comparables al "edificio X» de Kalavassos-«Agios Dimitrios», y al de Myrtou-«Pigades» o Flamoudi-«Vounari». Aprecia en él un fuerte carácter público, barajando incluso la posibilidad de que se tratase de un antecedente del santuario que luego ocuparía ese mismo lugar desde época arcaica a helenística, posiblemente dedicado a Deméter. 


\section{BIBLIOGRAFIA}

Baurain, Cl., 1984: Chipre et la Méditerranée orientale au Bronze Récent. Synthese historique, (Études chypriotes VI), Paris.

BONNET, Corinne, 1988: Melqart, cultes et Mythes de l'Héraclès tyrien en Méditerranée, en "Studia Phoenicia, VIII", Leuven.

BuchHOLz, H. G., 1974: “Tamassos, Zypern 1973», Archäologischer Anzeiger, pág. 554-614.

- 1973: “Tamassos, Zypern 1970-1972». Archäologischer Anzeiger, pág. 295-388.

- 1972: “Politiko-Tamassos 1971», Reports of the Departament of Antiquities, Cyprus, pág. 183-6.

Cadogan, G., 1985: "Maroni», en Archaeology in Cyprus 1960-1985. Nicosia, págs. 195-8.

Casson, Stanley, 1939: Chypre dans l'antiquite, Paris.

CAUBET, Annie, PIC, M., 1982: "Un culte hathorique à Kition-Baboula", en Archéiologie au Levant. Recueil R. Saidah, Lyon, págs. 237-249.

CaUbet, Annie. 1986. "Les sanctuaires de Kition à l'epoque de la dynastie phénicienne" Studia Phoenicia IV. Religio Phoenicia. Namur, pág. 153-68.

Charles, Robert P., 1962: Le peuplement de Chypre dans l'Antiquité, París.

Ganiers, J. DE, 1985: "Les Fouilles de I'Université Laval à Soloi», en Archaeology in Cyprus 1960-1985. Nicosia, págs. 256-61.

GJerstad, Einar, 1979: "The Phoenician Colonization and Expansion in Cyprus", en Reports of the Departament of Antiquities Cyprus.

- 1948: The Swedish Cyprus Expedition IV/2. Estocolmo.

- 1937: The Swedish Cyprus Expedition III. Estocolmo. 
Greebfiel, J. C., 1987: “Larnax tès Lapethou III revisited», Studia Phoenicia $V$. Phoenicia and the East Maditerranean in the 1 milenium. Leuven, pág. 391.

Hermary, Antoine, 1988: "Le culte d'Aphrodite à Amathonte", en Reports of the Departament of Antiquities Cyprus (part 2), págs. 101-10.

- 1987: «Amathonte de Chypre et les Phéniciens», en Studia Phoenicia $V$. Phoenicia and the East Maditerranean in the I milenium. Leuven, págs. 375-88.

- 1986: “Influences Orientales et Occidentales sur l'Iconographie des Divinites Chypriotes (VII-III a.C.)". Acts of the International Archaeological Symposium "Cyprus betwen the Orient and the Occident". Nicosia, págs. 405-11.

KarAgeORGHIS, Jacqueline, 1980: "La Grande Déese à Salamine», Salamine de Chypre. Histoire et Archéologie. Etat des recherches. (Lyon, 13-17 de marzo de 1978), Coloques Internationaux du CNRS, núm. 578. Paris.

- 1977: La Grande déese de Chypre et son culte à travers de l'iconographie de l'époque néolithique au VIe. siécle a. J.C., Maison de l'Orient (Collection de la Maison de l'Orient méditeranéen, núm. 5, Série Archéologique, núm. 4) Lyon, Paris.

Karageorchis, Vasos (ed.), 1985: Archaeology in Cyprus 1960-1985. Nicosia.

- 1982: Cyprus, from the Stone Age to the romans. Londres.

- 1979: "Materials from a sanctuary at Potamia", Reports of the Despartament of Antiquities, Cyprus, págs. 289-315.

- 1978: "A "Favissa" at Kakopetria", Reports of the Departament of Antiquities, Cyprus, págs. 156-96.

- 1977: Two Cypriote Sanctuaries of the end of the Cypro-Archaic Period. Roma, Cons. Naz. Ric.

- 1973: "Contribution to the religion of Cyprus in the XIII and XII centuries B. C.", Acts of the International Archaeologycal Symposium "The Mycenaeans in the Eastern Mediterranean, (Nicosia, 27-III a 2 IV 1972). Nicosia. págs. 105-9, pl. XIX.

- 1969: Salamis in Cyprus, Homeric, Hellenistic and Roman, Londres.

Maier, F. G., WARTBURG, M. L. V., 1985: «Reconstracting history from the Earth, c. 2800 V. C. 1600 A. D., Excavating at Palaepaphos, 19661984", en Archaeology in Cyprus 1960-1985. Nicosia, págs. 142-72.

MAIER, F. G., 1975: "The temple of Aphrodite at old Paphos", Reports of the Departament of Antiquities, Cyprus, págs. 186-201.

- 1972: "Excavations at Kouklia (Palaepaphos)", Reports of the Departament of Antiquities, Cyprus, pág. 186-201. 
MAsson, O., 1973: “Remarques sur les cultes chypriotes a l'epoque du Bronze Recent, Acts of the International Archaeologycal Symposium. The Mycenaeans in the Eastern Mediterranean, (Nicosia, 27-111 a 2 IV 1972), Nicosia, págs. 110-21.

- 1971: "Kypriaka IX: Recherches sur les antiquités de Golgoi», Bulletin de Correspondance Hellénique, 92, págs. 402-9.

- 1964: "Kypriaka I: Rechercher sur les antiquités de Tamassos», Bulletin de correspondance Hellénique, 88, págs. 199-238.

- 1960: Cultes indigénes, cultes grecs et cultes orientaux a Chypre, dans la religion grecque ancienne, Paris.

Michaelidou-NicolaOU, I., 1987: "Repercusions of the Phoenician Presence in Cyprus", en Studia Phoenicia V, Leuven, págs. 331-38.

MLYNARCZYK, Jolanta, 1986: "The Paphian sanctuary of Apolo Hylates", Reports of the Departament of Antiquities, Cyprus, págs. 239-52.

NicolaOU, K., 1978: "Oriental Divinities Represented on the Clay Sealings of Paphos, Cyprus", en Hommages à M. J. Vermaseren 11. Leyden, págs. 849-53.

Poullloux, J.: 1973: “Artemis Paralia à Kition", Acts of the International Archaeologycal Symposium "The Mycenaeans in the Eastern Mediterranean, (Nicosia, 27-III a 2 IV 1972), Nicosia. págs. 411-22.

RACHET, Guy, 1983: Dictionnaire de l'Archéologie. Paris.

SCHMID, M. E., 1988: "L'Architecture du Temple d'Aphrodite à Amathonte", en Reports of the Departament of Antiquities (part 2), Cyprus, págs. 143-9.

SOREN, D., 1973: "The Apollo Sanctuary at Kourion: Introductory Summary of the Excavarions and its Significance", Acts on the International Archaeological Symposium "The Mycenaeans in the Eastern Mediterranean, (Nicosia, 27-III a 2 IV 1972), Nicosia. págs. 393-403.

YON, Marguerite, CAUBET, Annie, 1988: “Un cultes populaire de la Grande Déese à Lapithos", en Reports of the Departament of Antiquities, Cyprus (part. 2), págs. 1-17.

YON, Marguerite, 1986: “Cultes phéniciens à Chipre: l'interpétation chypriote", en Studia Phoenicia IV, Religio Phoenicia. Namur, págs. 12752.

- 1985: "Mission Archéologique Française de Salamine: La ville Bilan, 1964-1984", en Archaeology in Cyprus 1960-1985. Nicosia, págs. 202-18. 